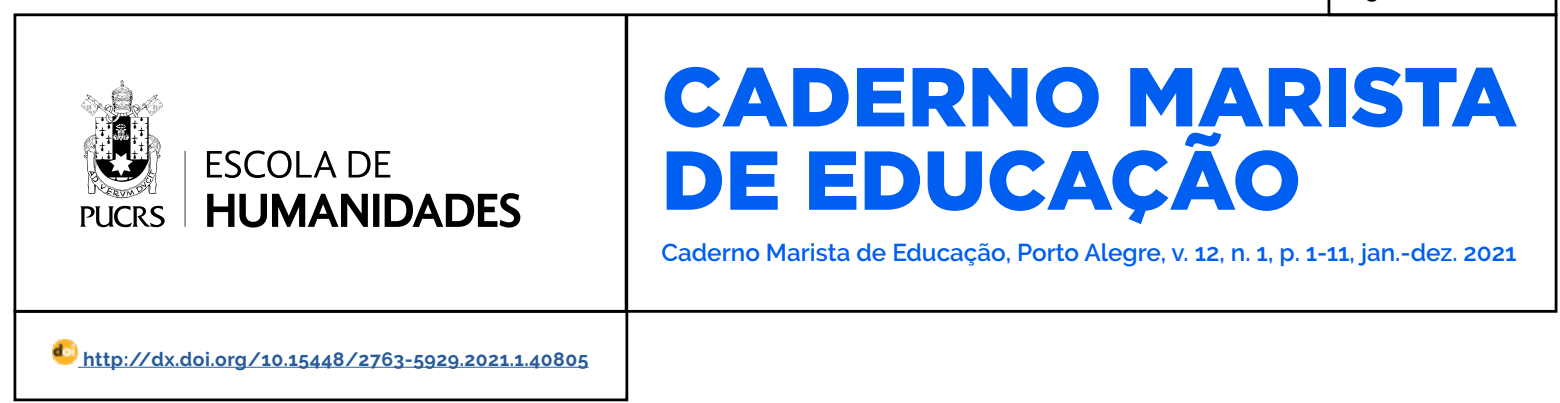

SEÇÃO: ARTIGOS

\title{
A mediação de literatura infantil em biblioteca escolar
}

Children's literature reading mediation at school libraries

\section{Simone Kniphoff dos \\ Santos $^{1}$}

orcid.org/0000-0002-2678-9316

simone.knip@gmail.com

Recebido em: 23 abr. 2021 Aprovado em: 17 jun. 2021. Publicado em: 23 set. 2021.

\section{(c) (i)}

Artigo está licenciado sob forma de uma licença Creative Commons Atribuição 4.0 Internacional.
Resumo: O objetivo principal deste artigo é ampliar as visões sobre as práticas de incentivo à leitura literária no ambiente das bibliotecas escolares. Sob esse propósito, procurou-se descrever e analisar algumas atividades já praticadas em uma instituição de ensino privado em Porto Alegre. Para tanto, foi realizada uma pesquisa bibliográfica a partir da literatura disponivel sobre o tema. Baseado nisso, constatou-se que a mediação de leitura com textos da literatura infantil e juvenil tendem a estimular o interesse dos estudantes pelas histórias e possibilitar uma relação de familiaridade com o espaço em que a atividade de mediação é realizada, tendo potencial para trazer grandes benefícios não somente para sua trajetória escolar, mas para a vida.

Palavras-chave: Mediação de leitura. Literatura infantil. Biblioteca escolar.

Abstract: The main goal of this article is to increment the practices to encourage literary reading in school libraries. Some activities currently employed at a private institution of Porto Alegre were described an analyzed. To make that happen, a bibliographic research was conducted from available literature on the subject. Based on that, it was found that reading mediation with children's and youth's literature tend to promote student engagement and enables an acquainted relation with the mediation environment. It brings major benefits, not only for school, but also for life.

Keywords: Reading Mediation. Children's Literature. School Library.

\section{Introdução}

Este artigo é resultado de estudos teóricos e trabalhos práticos voltados para a literatura e sobre a importância dos estímulos à leitura literária no espaço da biblioteca escolar, principalmente com os estudantes das séries iniciais do ensino fundamental e educação infantil, pois este público possui em sua rotina um período dedicado a frequentar a biblioteca para empréstimos e mediações de leitura. Ao realizar como função principal as atividades de mediação de leitura para os estudantes e instigar o diálogo sobre os textos após a atividade expositiva, percebeu-se que essas práticas proporcionam às crianças diferentes vivências com os sentidos e experiências com a linguagem, ou seja, possibilitam o desenvolvimento linguístico e cognitivo, além de corroborarem para ampliação de suas visões de mundo e apreciação do prazer estético que apenas textos literários podem nos proporcionar, conforme reafirmado ao decorrer deste trabalho pelos excertos teóricos indicados.

São realizados muitos debates sobre a importância da leitura no periodo de alfabetização, entretanto, geralmente se voltam para questões 
relacionadas à internalização das estruturas da lingua, enquanto o prazer estético ao apreciar uma narrativa, bem como a ampliação de seu repertório cultural e a ludicidade da obra (também fatores a serem levados em conta) acabam por ser menorizados. Tendo em vista que trabalhar com literatura na escola é essencial para a formação humana do individuo, pois observa-se que essa área do conhecimento estimula a empatia com o próximo ao vivenciar outros contextos pelos diferentes universos experenciados nos textos literários, a desvalorização dessa outra potência dos textos acaba por prejudicar a formação dos leitores na escola.

Além disso, se faz necessário explicitar o conceito de biblioteca escolar, visto que é uma tipologia de biblioteca peculiar e diferenciada: pelos seus usuários, materiais e necessidades informacionais. Dentre todas as tipologias de bibliotecas, a escolar é a porta de entrada deste tipo de ambiente para a maioria das pessoas e, dessa maneira, acaba por marcar a imagem que os cidadãos criam sobre esses espaços por toda sua a vida, ou seja, é uma grande responsabilidade atuar em bibliotecas e desmitificar os conceitos negativos estabelecidos ao longo da história pela sociedade.

Assim, essa pesquisa foi realizada com o propósito de enriquecer os trabalhos debruçados em leituras literárias que vêm sendo realizados em bibliotecas escolares. Além disso, busca-se ressaltar a relevância de procurar novas alternativas para não se cair nos processos rotineiros sobre suas práticas; valorizar o fruir dos saberes impregnados nos textos mediados, a experiência com o prazer estético propiciado pelas leituras, bem como os momentos de compartilhamento das vivências dos estudantes após as mediações de leitura literária, com o objetivo de aproximá-los não apenas dos textos, mas também criar vínculos com o espaço em que a atividade ocorre.

\section{Curadoria literária}

Entre as grandes questões que inquietam no trabalho de textos literários com os estudantes, umas das principais são as que pairam no momento de seleção da obra. É uma grande respon- sabilidade indicar um texto, pois neste instante estamos deixando de escolher muitos outros. E, diante de um amplo acervo, tantas opções para se trabalhar, como escolher obras de alto grau estético para a mediação de leitura? O que torna um texto literário? A fim de responder tais questões sobre como definir qual texto possui valor literário, Proença Filho (2003, p. 6) declara que:

Percebemos, desde logo, que estamos diante de uma utilização especial da lingua que falamos. O ritmo que caracteriza o texto, a natureza do que se comunica e, ao chegar até nós por escrito, a distribuição das palavras no espaço do papel, justificam essa conclusão.

Além disso, o autor citado expõe questões como a ambiguidade que o texto pode gerar, os simbolismos por trás das palavras de um texto literário, significações que, como afirma, vão além do real concreto. Dessa maneira, enquanto na fala cotidiana se busca trazer a informação da maneira mais clara e objetiva possivel, no texto literário há uma busca estética envolvida, a linguagem deixa de ser apenas um instrumento da informação.

Proença (2003, p. 14) também declara que:

É consenso, entretanto, que, no texto literário, se configura uma situação que passa a 'existir' a partir dele como tal e que caracteriza uma apreensão profunda do homem e do mundo, a partir de tensões de caráter individual ou coletivo.

Ou seja, o texto literário vai além de uma reprodução ou imitação da realidade, o escritor destaca sua visão sobre as coisas de uma maneira ainda não vista, refletida, cria um novo real com uma certa universalidade, pois, como aponta o autor, uma das maneiras que o homem utiliza para conhecer e refletir sobre o mundo é a arte.

Ao escrever um texto, o individuo tem um vasto repertório de termos a utilizar, e a seleção que executa marca o seu, ainda nas palavras de Proença, "ideal linguístico", ou seja, o seu estilo. Assim, a linguagem empregada no texto é um forte parâmetro para estabelecer informações como, por exemplo, identidade dos personagens e do narrador (no caso dos textos do gênero narrativo), portanto é uma das marcas na forma do texto que o autor estabelece. 
E, para esse universo criado pelo autor ser compreendido, o conhecimento daquele que recebe a mensagem tem de ser suficiente para a decodificação e interpretação do texto. Proença (2003, p. 7-8) aponta que: "O texto se repercute em nós na medida em que revele emoções profundas, coincidentes com as que em nós se abriguem como seres sociais". Lajolo nos traz vários exemplos de autores que voltam suas escritas para o universo infantil e juvenil ao afirmar que:

Literatura para crianças e jovens? Tem, sim senhor, e é Literatura com L maiúsculo! Vá conferir com Ana Maria Machado, Ângela Lago, Anna Cláudia Ramos, Fernando Vilela, João Carlos Marinho, Luiz Antônio Aguiar, Odilon de Morais, Pedro Bandeira, Ricardo Azevedo, Roger Mello, Roseana Murray, Ruth Rocha... tantos outros! [...] De tudo um pouco, com menos ou mais estrelas, mas com direito assegurado a território no mapa e espaço no livro. E é esse reconhecimento que faz a diferença. Faz tempo que se escreve para crianças (LAJOLO, 2018, p. 70-71).

Dessa maneira, percebe-se a importância da leitura para a transformação do indivíduo, mas a literatura em si deve prestar para algo? Essa questão é muito debatida em cursos na área, a literatura não deve prestar para nada, conforme Britto aponta (2015, p. 53): "[...] a literatura não forma nem conforma os espíritos, não salva nem consola, não ensina, nem estimula. Enfim, não se presta muito para coisas práticas e aplicadas. Não produz realidades mensuráveis e negociáveis". Restringir o trabalho com a literatura com motivos objetivos e fechados para ser trabalhada na escola pode fazer com que os professores que medeiam a leitura caiam em equivocos que Petit ressalta em sua obra:

[...] sempre se temeu o acesso direto ao livro e a solidão do leitor diante do texto. É por essa razão que, ainda hoje - tocaremos nesse ponto ao tratarmos do medo do livro -, os poderes autoritários preferem difundir vídeos, fichas ou trechos escolhidos, acompanhados de sua interpretação e contendo a menor possibilidade de 'jogo', deixando ao leitor a mínima liberdade (PETIT, 2009, p. 27).

Entretanto, a afirmação isolada de que a literatura não presta para nada sempre foi algo que causou incômodos, pois há de se ter nos textos mais do que isso para todos os movimentos que as obras literárias já causaram na existência de tantas pessoas. Petit aborda essa discussão ao redigir o capítulo "O leitor 'trabalhado' por sua leitura". Nele ressalta as possibilidades de diálogos entre leitor e o texto:

[...] O leitor não é passivo, ele opera um trabalho produtivo, ele reescreve. Altera o sentido, faz o que bem entende, distorce, reemprega, introduz variantes, deixa de lado os usos corretos. Mas ele também é transformado: encontra algo que não esperava e não sabe nunca onde isso poderá levá-lo (PETIT, 2009, p. 29).

Ao ler o texto já citado de Britto, percebe-se que o autor também sente aflições similares, sobre essa afirmação isolada, ao redigir o capítulo: "As razões do direito à literatura", pois, ao mesmo tempo em que aponta a questão de a literatura não servir para nada, também descreve como a literatura presta para tudo:

[...] O texto literário é um convite a uma ação desinteressada, gratuita, uma ação que não espera que dela resulte lucro ou benefício. É o simples pôr-se em movimento, para sentir-se e existir num tempo suspendido na história, um tempo em que a pessoa se faz somente em si, para ser, um tempo de indignação e contemplação, de êxtase e sofrimento, de amor e angústia, de alivio e esperança, disso tudo de uma só vez e para sempre. Nela a gente se forma e se conforma, perde-se e salva-se, se consola e se estimula, aprende e ensina a viver em realidades incomensuráveis, ainda que realmente intangiveis (BRITTO, 2015, p. 53).

Nos textos literários, é possível a vivência de muitas vidas que vão além do que imaginamos dentro do nosso universo possível de acordo com a realidade social e cultural em que vivemos. Colasanti descreve esse universo literário, que a marcou na infância, com um relato muito direto ao abordar exemplos retirados de contos de fadas como:

Nenhum lobo escondido entre troncos teria me ensinado a lidar com os outros lobos, bem mais famintos, que haveria de encontrar vida afora. Nenhuma fera teria me mostrado a beleza da compaixão. O patinho feio que eu era não teria tido nenhum aceno convincente da possibilidade de transformação. E sem a princesa pálida como a neve deitada no seu esquife de cristal e devolvida à vida por um beijo, quem me diria da força vivificadora do amor? (COLASANTI, 2012, p. 21). 
Dessa maneira, quanto a esses movimentos proporcionados pela experiência literária, tanto externo quanto internos, se pode afirmar que são essenciais na construção da identidade dos individuos ao se deparar também com reflexões como esta:

[...] E na literatura, em particular, encontramos palavras de homens e mulheres que permitem dizer o que temos de mais intimo, que fazem parecer, à luz do dia, aquele ou aquela que não sabiamos que éramos. Palavras, imagens, nas quais encontramos um lugar, que nos acolhem e que desenham nossos contornos. Palavras que fazem pensar [...] (PETIT, 2009, p. 53-54).

Portanto, definir o que é ou não um texto literário é uma ação para a qual se necessita ponderar uma série de características, conforme expressas nesse capítulo. Mas, o fato de um texto afetar ou não um leitor é algo pessoal e que depende de uma série de variáveis (contexto social do leitor, experiências adquiridas, relações de amadurecimento com si mesmo e com a sociedade) que são dificeis de mensurar pelo profissional que está a indicar uma obra na biblioteca. Ainda assim, disponibilizar e aproximar pessoas de textos literários são ações pertinentes para o desenvolvimento do ser humano e, consequentemente, da sociedade.

\section{A biblioteca escolar}

A biblioteca escolar é um ambiente que propicia aprendizagem, por meio de leituras e vivências. O seu acervo precisa ser didático, cultural, recreativo e oferecer materiais de acordo com as necessidades da comunidade escolar. Logo, o público desses espaços se apresenta com diferentes faixas etárias, pois segundo os autores Moro et al. (2011, p. 86) ressaltam, "[...] A Biblioteca Escolar se caracteriza como função pedagógica e abrange uma 'clientela' ampla e de diversos niveis de escolaridade, pois seus usuários pertencem à faixa etária dos dois aos oitenta anos, desde a Educação Infantil ao Pós-Médio [...]".

Dessa maneira, esse espaço de aprendizado necessita ser aberto e acessivel, promovendo atividades de interação entre seu público. Em outras palavras, precisa ser um local de conexões entre informações e pessoas. Para isso, é essen- cial que a biblioteca seja vista como o coração da instituição e precisa estar de acordo com o currículo escolar. Sobre o espaço e o profissional que ali atua, Roca afirma que:

Todas as ações da biblioteca - deverão ser concebidas e, por sua vez, essas ações são necessárias como bases que garantam a estabilidade da função de apoio que a biblioteca assume - como uma necessidade derivada do seu uso enquanto recurso educacional. Esta apoia e facilita, de forma geral, o desenvolvimento do projeto da escola e, de forma real, o desenvolvimento de conteúdos curriculares das diferentes áreas. O responsável pela biblioteca é um profissional que colabora com os professores, apresentando-se como um especialista e um referencial a recorrer para as questões relacionadas aos conteúdos curriculares da leitura, da formação literária e da competência informacional (ROCA, 2012, p. 20-21).

Por essa perspectiva, vemos que a escola é fundamental no suporte de descobrimento da leitura, em que muitas crianças têm o primeiro contato com este mundo apenas quando iniciam suas atividades escolares, o que infelizmente, diferencia-se muito de crianças que já têm contato com leituras antes de iniciar a fase escolar. Levando-se em conta esse olhar sobre a necessidade de se promover a leitura dentro e fora da escola, em diferentes contextos socioeconômicos, a teórica já citada reflete que:

Evidentemente, a biblioteca escolar pode e
deve ser utilizada pelos estudantes de forma
autônoma sempre que quiserem e puderem
dentro e fora do horário escolar. Isso deve ser
facilitado, bem como a promoção de seu uso
por parte das familias, no caso das escolas de
educação infantil e fundamental. Da biblioteca,
pode-se conduzir um interessante trabalho
de apoio à promoção da leitura nos lares e,
também, um projeto estruturado de atenção às
necessidades especiais e à compensação de
desigualdades educacionais (ROCA, 2012, p. 31).

De acordo com essa reflexão exposta, a biblioteca escolar possui uma função não apenas educacional, mas também social na formação dos indivíduos, tendo em vista que muitas vezes, além de ser o primeiro, esse é o único espaço que o estudante possui para aprofundar seus estudos e estar em contato com os saberes estimulados em aula. Segundo reflete Riter (2009, p. 26) "O livro não havia na biblioteca do SESI. E isso significava tudo. 
Significava a impossibilidade vital de encontrá-lo novamente. Nosso universo de leitores tinha os limites das paredes daquela biblioteca. [...]".

Logo, esse espaço acaba por ser o local em que os profissionais que ali atuam podem dar um maior suporte para manter a leitura na rotina estimulada pelo professor ou pelas trocas com os colegas. A relação positiva dos profissionais na escola com os estudantes pode gerar marca por toda a vida leitora dos pequenos, conforme reflete Goldin (2012, p. 32): "Gostava quando a bibliotecária me dizia que eram para adultos. Eu respondia que não importava: ler havia se tornado uma fonte de prestígio social, embora também continuasse como fonte de prazer e de inúmeras emoções".

Se o profissional do exemplo acima tivesse proibido a criança de retirar o livro que queria ou se não mantivesse uma relação positiva com ela, talvez o relato do teórico sobre sua experiência com a leitura na infância fosse muito diferente de como nos relata. Logo, a sala de aula é onde comumente se inicia o processo de alfabetização e os trabalhos com os diferentes tipos de texto e a biblioteca acaba por se tornar o local de suporte para novos encontros e aprofundamento dessas e outras descobertas do mundo.

Conforme Roca (2012, p. 32) ressalta sobre as práticas de leitura literária, "as iniciativas também podem vir da biblioteca, desde que estejam sempre localizadas em um contexto específico ou respondam a uma necessidade da escola". Assim, a biblioteca escolar precisa ser um ambiente em que o bibliotecário e o corpo pedagógico da escola trabalhem em sintonia, em que as atividades em aula possam ser complementadas com ações realizadas na biblioteca ou ainda ir além dessas.

Entretanto, é preciso ponderar o contexto do meio em que se encontra a biblioteca escolar em questão. Cada instituição (pública ou privada), mesmo com regras comuns, tem focos maiores ou menores no desenvolvimento de setores de apoio ao ensino na escola. Daí a importância de bibliotecas escolares possuírem um quadro de funcionários preparados e engajados para prestarem os serviços disponibilizados e conquistarem melhorias para as bibliotecas. De acordo com o Manifesto IFLA/ UNESCO${ }^{2}$, nas bibliotecas escolares:

Está comprovado que bibliotecários e profes-
sores, ao trabalharem em conjunto, influenciam
o desempenho dos estudantes para o alcance
de maior nível de literacia na leitura e escrita,
aprendizagem, resolução de problemas, uso da
informação e das tecnologias de comunicação
e informação (UNESCO, 2002, p. 2).

Conforme Cosson (2014, p. 32) reflete em seu texto, o cenário da maioria das bibliotecas escolares no ensino público no Brasilé bem negativo "[...] na maioria das escolas brasileiras, a biblioteca, quando existe, é sinônimo de sala do livro didático, não tem funcionários preparados para incentivar a leitura e apresenta coleções tão reduzidas e antigas que um leitor desavisado poderia pensar que se trata de obras raras".

Em relação a essas questões, as Diretrizes IFLA/UNESCO para as Bibliotecas Escolares define que faz parte da missão para esse tipo de espaço:

[...] propiciar informação e ideias que são funda-
mentais para o sucesso de seu funcionamento
na sociedade atual, cada vez mais baseada na
informação e no conhecimento. A biblioteca
escolar habilita os alunos para a aprendizagem
ao longo da vida e desenvolve sua imagina-
ção, preparando-os para viver como cidadãos
responsáveis (UNESCO, 2005, p. 4).

Pensando nessas realidades, as instituições vêm procurando ampliar seus trabalhos com leitura literária e formação do leitor por meio de atividades que estimulem a leitura, mas também abra espaço para a aproximação com os estudantes por meio do diálogo após as atividades. Com essas iniciativas, a biblioteca passa a assumir novas funções para o público escolar e possibilidades de novas experiências, pois, conforme Roca aponta:

[...] a biblioteca é facilitadora da criação de ambientes pessoais e coletivos de leitores que permitem experiências de leitura sig-

2 O documento criado pela IFLA (Federação Internacional de Associações de Bibliotecários e Instituições) e a UNESCO (Organização das Nações Unidas para a Educação, a Ciência e a Cultura) foi publicado no ano de 2000 para dar suporte e orientação à comunidade bibliotecária e à sociedade como um todo. 
nificativas no âmbito emocional. Contextos em que a experiência literária possibilita um descobrimento da dimensão poética da vida e um conhecimento singular do mundo por meio dos relatos (ROCA, 2012, p. 30).

Assim, os espaços disponibilizados podem agregar para a formação de leitores ao aderir a abordagens de mediação e estímulo à leitura que aceita os múltiplos olhares e as possibilidades de desenvolvimento dos individuos pelas experiências com leituras literárias. Levando-se em conta, como discutido nos capítulos anteriores, que essa experiência é individual, de acordo com o contexto social e cultural de cada um, e de dificil mensuração se vista sob um olhar objetivo e fixo. Ou seja:

[...] a leitura e a biblioteca podem contribuir para verdadeiras recomposições da identidade. É claro que identidade não é entendida aqui como algo fixo, parado em uma imagem, mas ao contrário, como um processo aberto, inacabado, uma conjunção de traços múltiplos, sempre em transformação. Essas recomposições ocorrem numa relação com o que 'está aí, o conteúdo de uma biblioteca, uma cultura, um patrimônio. Porém, não se trata de um patrimônio imutável, petrificado, ao qual nos submetemos passivamente, para nos conformarmos às normas (PETIT, 2009, p. 53-54).

Dessa maneira, a biblioteca escolar pode ser considerada o coração da escola, o local onde todos os saberes se encontram, onde os estudantes compartilham conhecimentos e exercitam o que já foi estimulado com o professor. A biblioteca escolar pode ser o espaço para propiciar experiências positivas com a leitura, como define Goldin:

Quem sabe o horizonte da leitura seja apenas isso: uma linha tênue e distante entre o sol se põe ou se levanta, onde nascem, morrem ou renascem a claridade e a noite. E somos a noite e o dia. O estranho desamparado e o que acolhe e ampara, e também a casa onde esse encontro acontece. E não somos nada disso e somos alguém em busca de uma voz que nomeie e faça hospitaleiro esse vasto e indiferente território ao qual chamamos mundo (GOLDIN, 2012, p. 46).

É neste espaço que as situações promovidas no ambiente escolar são aprofundadas e expandidas. Nele que os sentimentos em torno do objeto livro são despertados ou estimulados. Conforme exemplificado pela vivência do escritor com um livro de sua infância, que mesmo sem o pertencer atualmente, ainda propicia a ele tantos sentimentos:

Perdi, no entanto, o objeto. A emoção de tê-lo encontrado, de tê-lo lido, ah não, essa não perderei jamais. Essa permanece tatuada na pele, no coração, no sangue, na memória. Para sempre. Livros são assim até hoje. Quero-os por perto. Quero-os para toque, para carinho em pele de papel. Quero-os como convite, como devoramento, como objeto vivo em sua capacidade de posse e de entrega (RITER, 2009, p. 29).

Assim, o ambiente familiar é importante para estimular a leitura entre as crianças, mas a escola é considerada o principal agente responsável pela formação de leitores no país. Nem sempre as instituições veem a biblioteca escolar como prioridade no estímulo da aprendizagem, por isso a luta para que esses espaços sejam vistos e valorizados é uma constante na vida de muitos educadores. Pois, são estes que percebem a relevância de um trabalho bem desenvolvido nestes espaços para o progresso de uma sociedade mais justa e igualitária.

\section{Mediação de leitura}

Se os estudantes já têm contato com a literatura dentro da sala de aula, por que mediar histórias é importante nos espaços disponiveis na biblioteca escolar? Se levarmos em conta um possivel olhar para a biblioteca escolar que julga que o espaço precisa ser um local de silêncio para que os estudantes possam fazer ali suas tarefas de aula, ou ainda realizar pesquisas científicas dentre as obras do acervo, o ato de mediar histórias e compartilhar experiências se torna um problema. Entretanto, são vários os benefícios que a mediação de leitura literária pode trazer para as crianças em uma biblioteca escolar. Por isso, este capítulo visa a esclarecer alguns desses e reforçar as práticas realizadas nesses ambientes que como bem pontua Rosa:
Lemos para os pequenos para provocar e desenvolver neles o gosto pela leitura, estimulando assim a sua criatividade - e também para que fiquem intimos das palavras podendo usar e abusar delas em qualquer contexto. É uma forma de fortalecer a amizade com a palavra escrita, o que facilitará a sua comunicação com as pessoas ao longo de sua vida. Lemos para 
que não tenham medo de se colocar no mundo, construindo a sua própria maneira de dizer e de se anunciar; para que vivenciem através de sua imaginação muitas outras experiências que só a história contada de um bom livro de literatura pode provocar (ROSA, 2017, p. 25-26).

Ao longo do ano letivo, o mais usual em bibliotecas escolares são as leituras expressivas, em que o texto é mediado pelo profissional que ali atua com ou sem uso de recursos, mas sempre de modo que traga uma possibilidade de recepção da obra com a disponibilidade de auxílio do profissional que ali atua como agente de leitura. No entanto, no trabalho com a literatura no Ensino Fundamental, Cosson destaca algumas características que aparecem com frequência no ambiente escolar ao se trabalhar com textos escritos de ficção ou poesia:

[...] O limite, na verdade, não é dado por esse parentesco, mas sim pela temática e pela linguagem: ambas devem ser compativeis com os interesses da criança, do professor e da escola., preferencialmente na ordem inversa. Além disso, esses textos precisam ser curtos, contemporâneos e 'divertidos' (COSSON, 2014, p. 21).

Logo, a escolha da obra a ser trabalhada nas atividades de leitura não é algo tão simples, pois se tem consciência de que toda escolha é arbitrária, mesmo que com embasamento, objetivo e planejamento. Nas mediações de histórias essa realidade também está presente e é no somatório entre a voz do educador e dos educandos que o trabalho é desenvolvido, sem longos monólogos, mas também com a preocupação de se manter a fluidez dos textos e da multiplicidade de sentidos presentes na construção pela palavra, pois, conforme defende a escritora:

Ouvir histórias é mais um momento de intimidade e de compreensão dos múltiplos sentidos das palavras e de sua sonoridade peculiar porque a palavra falada é mesmo muito amiga dos pequenos e proporciona grande prazer quando as crianças descobrem que podem brincar com ela (ROSA, 2017, p. 28).

Bem como manter a fluidez das narrações, há também uma preocupação em se manter a originalidade do texto. Assim, os livros trabalhados são expostos aos estudantes, de modo que os estudantes tenham consciência de que a ação apenas ocorreu a partir do trabalho do autor, ilustrador e, em alguns casos, tradutor. Conforme a teórica citada afirma:

[...] Aprecio muito a presença do livro nas rodas das contações de histórias dos contos populares porque acho interessante a criança visualizar que ali naquele livro tem aquela história que acabou de ouvir e que poderá ver as imagens e ler a história relembrando aquele momento em que a ouviu (ROSA, 2017, p. 45).

Sobre adentrar ao mundo do faz de conta, as assistentes de biblioteca têm liberdade para trabalhar com os recursos que acharem pertinentes para a história. Nem sempre os recursos são necessários, por vezes apenas a leitura expressiva com exposição das ilustrações ou efeitos sonoros na entrada dos estudantes ao ambiente já é suficiente para iniciar as atividades. Além disso, as brincadeiras com as palavras aproximam muito os estudantes das histórias e dos livros. O principal durante a mediação é o momento de partilha, dedicação e entrega de si para o outro e dos outros com o agente mediador, conforme declara o crítico literário Daniel Goldin sobre suas experiências de escuta da leitura literária pelo pai na infância:

[...] Hoje penso que gostava não apenas do relato. Encantava-me sentir meu pai dessa outra forma, dedicado a nós. Enquanto lia em voz alta, sua presença se expandia até um território inóspito, longínquo e tentador. Sua figura crescia ainda mais, porque eu intuía que ele lia para nós algo que lhe era importante [...] (GOLDIN, 2012, p. 28).

Quanto aos incentivos à leitura e o encantamento despertado por essas experiências, o autor Caio Riter (2009, p. 15) aborda a questão ao narrar um exemplo vivenciado em sua infância, em que ele relata: "[...] eu tinha que dizer bem rápido, mais rápido, as trocas de letras e de sons ocorrendo, a língua trancando, e o riso vinha farto saindo. A leitura virando mera brincadeira sonora".

E mesmo que o autor encerre o exemplo citado com o adjetivo "mera" ao se referir à leitura como brincadeira sonora, também demonstra profundo respeito por essa experiência. Riter (2009, p. 16) pontua a relevância dessa ação ao 
afirmar que "Brincar com as palavras não é luta vã. Ao contrário, é condição essencial para fazer brotar em corações ainda ternos, ainda fechados aos preconceitos, o amor pela leitura, o desejo de descoberta". Cecilia Meireles também reflete sobre essas questões ao afirmar que:

Por esse caminho, recebe a infância a visão do mundo sentido, antes de explicado; do mundo ainda em estado mágico. Ainda mal acordada para a realidade da vida, é por essa ponte de sonho que a criança caminha, tonta do nascimento, na paisagem do seu próprio mistério. Essa pedagogia secular explica-lhe, em forma poética, fluida, com as incertezas tão sugestivas do empirismo, o ambiente que a rodeia, - seus habitantes, seu comportamento, sua auréola (MEIRELES, 2016, p. 50).

Esses pontos são amplamente debatidos dentre a equipe de assistentes de biblioteca que compartilham as histórias desde a educação infantil ao quinto ano do ensino fundamental, pois há a preocupação de encantar os estudantes e desenvolver a equipe para tal. Outrossim, há sempre uma preocupação em trabalhar com assuntos que também motivem os discentes, é importante ter como prioridade o educando e suas possibilidades de relação com as obras. Para isso, a utilização de recursos nem sempre é algo fundamental, conforme aponta Rosa, o compartilhamento de uma história pode ser feito de muitas formas:

Os mediadores de leitura - bibliotecários, professores, pais e agentes de leitura, devem contar histórias para deleite dos ouvintes oferecendo a história como um abraço fraterno. Abrir um livro é libertar as palavras que moram dentro dele. As palavras ganham vida na voz de alguém e neste seu novo formato ganha um movimento próprio. Compartilhar uma história é contar, ler, mostrar as imagens do livro, conversar sobre os personagens e sobre a história ampliando e discutindo sobre o enredo (ROSA, 2017, p. 31).

Para que o envolvimento com a história ocorra, é preciso que os textos tenham relação com a realidade das crianças, com situações vivenciadas em seu dia a dia. Aqueles que já possuem uma proximidade com a leitura em casa, veem o livro com maior familiaridade, mas se sabe que em muitos casos não há leitores como exemplo a ser seguido pelos estudantes. O escritor Caio Riter aborda essa temática em sua obra e ressalta que em sua casa a mãe contava muitas histórias da cultura oral, mas outros exemplos de leitores foram os responsáveis pela aproximação com o livro como objeto, indiferente de seu conteúdo:

\begin{abstract}
Lembro ainda de meu pai e de minha irmã mais velha, a Maura, estarem sempre envolvidos com leitura. Não era leitura de livros. Ele lia livros de bolso: aventuras de detetive, de espionagem ou de faroeste; aventuras que, mais tarde fiquei sabendo, eram escritas por autores brasileiros. escondidos atrás de pseudônimos norteamericanos [sic] ou ingleses. Histórias simples, curtas, maniqueistas, em papel jornal, que atiçaram a minha imaginação de guri. A Maura mergulhava nas fotonovelas. Histórias de amor, fotografadas, feito gibis. Eram exclusivas para o público feminino, com suas tramas amorosas, repletas de peripécias, cujo final sempre era feliz. Um beijo selava a união do casal protagonista. Havia várias destas revistas: a Grande Hotel, a Contigo, a Sétimo Céu (esta era colorida e com artistas nacionais) (RITER, 2009, p. 23).
\end{abstract}

Após apresentar estes exemplos, Riter afirma que mesmo que as obras citadas fossem desprovidas de qualidade literária, foram importantes para sua formação como leitor. Essa vivência com livros em abundância, conforme já abordado nos capítulos iniciais deste trabalho, é muito importante para a promoção da leitura e aproximação dos estudantes com a biblioteca. É preciso apresentar a todos obras de diferentes gêneros e formatos, pois muitos precisam vivenciar diferentes tipos de textos para poder apreciar a qualidade estética presente nos textos literários. Ilan Brenman em seus apontamentos sobre formação de leitores nas escolas afirma:

Possivelmente um dos problemas encontra-
-se neste ponto: talvez nunca devêssemos
parar nem de contar e nem de ler histórias às
crianças e aos jovens. Quando estancamos
esta ação - podemos pensar - corremos o
risco, e é isso, parece, que está acontecendo:
pulam-se etapas em um processo lento e
profundo de ligação com as letras impressas.
Como ler Machado de Assis se não brincamos,
antes, com as palavras e com os livros? [...]
(BRENMAN, 2018, p. 121).

Por vezes, algumas bibliotecas escolares não dispõem de recursos para realizar mediações de histórias muito elaboradas. Entretanto, indiferente 
dos recursos financeiros presentes, o essencial é estar aberto a diferentes obras e considerar essa mediação substancial para a promoção do livro e da leitura, pois conforme afirma o autor:

A também necessária intermediação do adulto na formação de uma criança leitora. Livros à disposição e, quando não eles (na minha casa os motivos eram financeiros: familia grande. muitos filhos, pouco dinheiro), seres contadores de histórias ou apaixonados pelas palavras podem ser os despertadores do desejo da leitura. Estar aberto à fantasia é condição essencial para que os livros sejam procurados, suas páginas sejam abertas e as escolhas possam começar a serem feitas. O importante é a criação destes espaços de troca entre o que conta e/ou canta e aquele que escuta. Este, no futuro, com certeza também será ser de palavras (RITER, 2009, p. 24).

Muitas instituições de ensino trabalham o momento da mediação de leitura de uma maneira em que o profissional da mediação promove mais a si mesmo do que a obra que acaba por ficar em segundo plano. Se preocupam mais com artefatos como fantasias, maquiagens, investem recursos financeiros e intelectuais mais para como fazer do que para como escolher bem os textos e efetuar as ações de extrapolação da leitura (conforme será debatido no capítulo a seguir), sendo que, conforme a autora expõe:

Ouvir histórias é momento de encantamento e cumplicidade. Contar histórias com o livro na mão, em variados espaços como escolas, hospitais, casas, bibliotecas, espaços culturais, é dar vez à palavra falada como elo afetivo entre quem lê e quem escuta - condição fundamental para a melhoria das relações humanas na infância, possibilitando crescer com desenvoltura. Podemos contar histórias de diferentes maneiras: lendo a história do livro, mostrando ao final o livro da onde [sic] foi retirada a história contada. Cada contador de histórias tem a sua própria maneira de partilhar uma história. Particularmente, escolho sempre contar com o livro nas mãos, porque posso mostrar e promover o livro como um todo. Também me sinto mais confortável com este formato, já que não preciso decorar o texto, mas apenas senti-lo em sua essência. 'Conta de novo!'. É a maior alegria ouvir este pedido! Essa é a senha que revela que a contação de história foi bem-sucedida e a história foi bem recebida pelos ouvintes (ROSA, 2017, p. 37).

Assim, o ato de mediar leituras literárias tem seu valor e seu lugar dentro do ambiente da biblioteca escolar. As atividades apresentam aspectos positivos quanto ao estímulo e divulgação do espaço, temáticas e obras literárias, cativam os estudantes para o mundo da leitura, se mostrando válidas, desde que bem planejadas e com objetivos claros para a sua execução. Ou seja, a aproximação do estudante com os espaços de promoção da leitura é essencial para sua formação e dessa maneira se torna necessária a existência de um planejamento consistente e com objetivos claros dos trabalhos a serem desempenhados com a leitura literária.

Portanto, pensando na leitura como um espaço possivel de compartilhamentos, é preciso estimular o debate e a reflexão entre os estudantes, mediar as trocas de conhecimentos com as vivências de cada um, propiciando, assim, experiências positivas de aprendizagem, pois, conforme afirmam a Cagneti e Lira (2018, p. 35),

Saber ler, portanto, é dar conta de situar-se não somente no campo da linguagem, mas também no momento histórico da construção do texto lido, no espaço geográfico para o qual seu enredo nos remete, o momento político no qual estão inseridos seus personagens, e por aí vai.

E em seguida reforça essa ideia ao afirmar que "[...] Confrontar as diferenças aqui presentes é fundamental para que o leitor em formação descubra que mudados os tempos, mudam algumas práticas" (CAGNETI; LIRA, 2018, p. 35).

Com isso, é preciso debater e fomentar cada dia mais esse campo de estudo da aproximação das obras literárias nas bibliotecas escolares com os estudantes, estimular a capacidade dos estudantes de compreender os textos e seus possiveis desdobramentos. Sendo assim, é preciso levar em conta a possibilidade que a leitura literária fornece de ampliação da visão de mundo aos individuos, a fim de que se consolide uma sociedade mais empática, justa e igualitária. Como debatido por Cândido em suas falas e seus textos, ler não é uma opção do cidadão, mas sim um direito conquistado e que precisa ser exercido. Ouvir e aceitar a leitura do outro, agregar e se deixar afetar, torna a vida mais fácil, conforme defende Goldin: 
Não obstante, sustentar um respeito radical para que o outro continue sendo outro pode, sem dúvida, nos ajudar a fazer da terra um lugar menos infernal, mais complicado e interessante. Talvez, depois de tudo, o mundo seja sempre hostil e estranho, pois a terra, por mais bela que seja, é apenas o cenário impassivel de um drama que lhe é indiferente. Talvez, depois de tudo, nossa única morada seja a linguagem. E, se for assim, os livros poderiam ser a melhor forma de construi-la, desde que, como rezavam os antigos preceitos, tenham sempre a porta aberta para o estranho, e que nós mesmos possamos ser também esse estranho ao acolhermos nosso próprio estranhamento (GOLDIN, 2012, p. 107).

Como o trabalho praticado vai além do que é exigido no currículo escolar e se integra como um momento lúdico para estimular os estudantes nas escolhas de obras, ampliar seu repertório de experiências literárias, não é realizado um controle avaliativo dos resultados dessas ações. Os planejamentos das práticas leitoras - em que constam as descrições de itens como intencionalidade, motivação, extrapolação e referências utilizadas - são mantidos para compor o relatório anual enviado pela bibliotecária coordenadora da instituição, junto a outras informações como controle do fluxo de empréstimos e aquisições de obras realizado no espaço.

\section{Considerações finais}

A obra literária pode ser fonte de prazer estético e conhecimento, com sua leitura se pode conhecer diversas culturas, experiências e andar por outros mundos. Estimular na criança o prazer no ato da leitura de literatura, propiciar a oportunidade para que ela crie um vínculo com os livros, é uma tarefa muito importante. Nesse contexto, as bibliotecas escolares são relevantes para a formação do leitor, quando apresentam atividades de aproximação dos estudantes com os textos literários.

Realizar essas atividades na biblioteca escolar requer um olhar para este espaço como um local de disseminação do conhecimento e do encantamento com a literatura e não somente nos recursos de retiradas de livros ou consultas, mas de levar as histórias para sempre na memória por meio das vivências que foram ali propiciadas, pelas ideias que foram expostas e debatidas. Dessa maneira, a política do silêncio na biblioteca escolar entra em desuso, à medida que, além de estarmos lidando diretamente com crianças e adolescentes, é preciso que o estudante possa se manifestar nesse espaço e, para que isso aconteça, ele precisa sentir-se à vontade, é preciso compartilhar e acolher.

O educador que atua como professor de leitura literária e que pretende tocar seus ouvintes precisa estar atento ao fato de que, por ser uma atividade contínua, o interesse dos estudantes pode diminuir ao longo do tempo. Há diferenciais capazes de fazer prender a atenção das crianças, sendo o principal deles a relação positiva estabelecida nos momentos de diálogo.

Com o desenvolvimento do trabalho, percebeu-se que os profissionais que atuam na biblioteca são relevantes para os estudantes se sentirem acolhidos. É preciso que cada vez mais as portas estejam abertas para o público e as obras chamem sua atenção. Por esses motivos, o trabalho com leitura literária é tão importante. Ao realizá-lo em grupos, os discentes se apropriam dos livros, vivenciam a experiência literária ao passo que se sentem capazes de compreender e criar além dos textos.

A partir desses apontamentos, conclui-se que se for possivel fazer com que o momento dos estudantes no espaço escolar seja repleto de atividades construtivas, haverá contribuições significativas na formação desses leitores, pois, eles se sentirão estimulados a conhecer outras histórias, alcançando, assim, o objetivo final, que é fazer com que seja despertado o interesse pela leitura de textos literários com o estímulo da prática constante de leitura e a aproximação dos estudantes com a biblioteca.

\section{Referências}

BRENMAN, Ilan. Através da vidraça da escola: formando novos leitores. 3. ed. Belo Horizonte: Aletria, 2018.

BRITTO, Luiz Percival. Ao revés do avesso. São Paulo: Pulo do Gato, 2015.

CAGNETI, Sueli; LIRA, Áurea Rocha. Basta ler para ser leitor? Porto Alegre: Paulinas, 2018.

COLASANTI, Marina. Como se fizesse um cavalo. São Paulo: Pulo do Gato, 2012. 
CosSON, Rildo. Letramento literário: teoria e prática. 2. ed. São Paulo: Contexto, 2014

GOLDIN, Daniel. Os dias e os livros. Tradução de Carmen Cacciacarro. São Paulo: Pulo do Gato, 2012

LAJOLO, Marisa. Literatura: ontem, hoje, amanhã. São Paulo: Editora Unesp, 2018.

LIMA, Aldo de (org.). O direito à literatura. Recife: Ed. Universitária UFPE, 2012

MEIRELES, Cecilia. Problemas da literatura infantil. 4. ed. São Paulo: Global, 2016.

MORO, Eliane Lourdes da Silva; ESTABEL, Lizandra Brasil; SERAFINI, Loiva Teresinha; KAUP, Uli (org.). Biblioteca Escolar: presente. Porto Alegre: Evangraf, 2011.

PETIT, Michèle. Os jovens e a leitura: uma nova perspectiva. Tradução de Celina Olga de Souza. 2. ed. São Paulo: Editora 34, 2009

PROENÇA FILHO, Dominício. A linguagem literária. São Paulo: Ática, 2003

RITER, Caio. A formação do leitor literário em casa e na escola. São Paulo: Birutta, 2009.

ROCA, Glória Durban. Biblioteca escolar hoje: recurso estratégico para a escola. Tradução de Carlos Henrique Lucas Lima. Porto Alegre: Penso, 2012.

ROSA, Sonia. Entre textos e afetos: formando leitores dentro e fora da escola. Rio de Janeiro: Malê, 2017.

UNESCO. Manifesto IFLA/UNESCO para biblioteca escolar. São Paulo: IFLA/UNESCO, 2002. Disponivel em: https://archive.ifla.org/VII/s11/pubs/portuguese-brazil.pdf. Acesso em: 24 jan. 2021.

UNESCO. Diretrizes da IFLA/UNESCO para a biblioteca escolar. 2005. Disponivel em: https://archive.ifla.org/ VII/s11/pubs/SchoolLibraryGuidelines-pt_BR.pdf. Acesso em: 24 jan. 2021.

\section{Simone Kniphoff dos Santos}

Especialista em Teoria e Prática da Formação do Leitor pela Universidade Estadual do Rio Grande do Sul (UERGS), em Porto Alegre, RS, Brasil; especialista em A Moderna Educação: Metodologias, Tendências e Foco no Aluno pela Pontifícia Universidade Católica do Rio Grande do Sul (PUCRS), em Porto Alegre, RS, Brasil; Atuou como assistente de biblioteca no Colégio Marista Rosário, em Porto Alegre, RS, Brasil

\section{Endereço para correspondência}

Simone Kniphoff dos Santos

Colégio Marista Rosário

Praça Dom Sebastição, 02

Independência - 90035-080

Porto Alegre, RS, Brasil
Os textos deste artigo foram revisados pela Poá Comunicação e submetidos para validação da autora antes da publicação. 